\title{
Preliminary Design of an Augmented Railgun \\ Influence of the Dimensions of the Outer Rails on the Forces Acting on the Projectile and the Rails
}

\author{
Mieke Coffo Non-member (Royal Military Academy, mieke.coffo@rma.ac.be) \\ Johan Gallant Non-member (Royal Military Academy, johan.gallant@rma.ac.be)
}

Keywords : rail launchers, electromagnetic forces, ANSYS

Railguns are electromagnetic launch systems which have the potential to accelerate projectiles to velocities higher than $2 \mathrm{~km} / \mathrm{s}$. The acceleration of the projectile is the result of the interaction of the current through the brush armature with the magnetic field induced by the current in the rails. For a conventional railgun, raising the current is the best way to increase the electromagnetic force on the projectile. The current density however is limited: the heating of the sliding contacts between the rails and the brush armatures due to the Joule-effect and to the friction can cause the melting of these contacts. One way to increase the acceleration without raising the current through the projectile is by adding an extra pair of rails in order to establish an additional magnetic field. The EM force on the projectile for an augmented railgun is described by the force-equation:

$\mathrm{F}_{\mathrm{EM}}=1 / 2 \mathrm{~L}_{\mathrm{R}} \mathrm{I}_{\mathrm{R}}{ }^{2}+\mathrm{M}^{\prime} \mathrm{I}_{\mathrm{R}} \mathrm{I}_{\mathrm{A}}$

The first term represents the influence of the magnetic field induced by the current in the inner rails and is proportional to the self inductance gradient $\mathrm{L}_{\mathrm{R}}$. The second term describes the influence of an additional magnetic field and is proportional to the mutual inductance gradient $M^{\prime} . I_{R}$ and $I_{A}$ are respectively the currents in the inner and outer rail.

The objectives of this preliminary study are to design an augmented railgun capable of accelerating projectiles with a mass of 100 to $200 \mathrm{~g}$ to a velocity of 1 to $2 \mathrm{~km} / \mathrm{s}$, with the condition that the EM forces on the rails must be limited to $8 \mathrm{MN} / \mathrm{m}$.

The finite element code ANSYS was used for the simulation of the magnetic fields. Three current ratios were used for the simulations. The forces acting on the rails are determined with a 2D transient analysis. The EM force on the projectile is analytically calculated with the force-equation. Therefore values of $\mathrm{L}_{\mathrm{R}}$ and $\mathrm{M}$ ' are determined with a $3 \mathrm{D}$ AC-analysis at frequencies of $10 \mathrm{~Hz}$ and $1 \mathrm{kHz}$. For each geometry and frequency the EM force for the three current ratios were determined. The force-equation (1) is then used to determine $L_{R}$ and $M$ ' for each geometry at both frequencies by fitting ${ }^{(1)}$. The EM force on the projectile calculated with a $3 \mathrm{D}$ transient analysis was then compared with the analytically determined results for the same

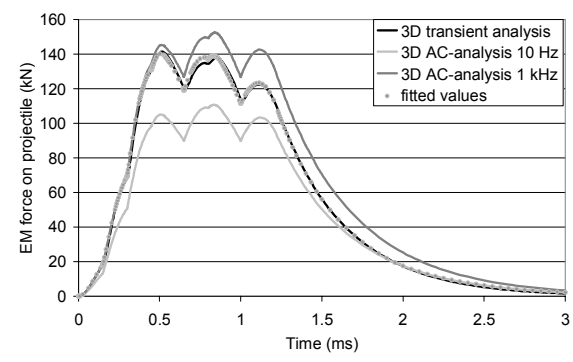

Fig. 1. EM force on the projectile: Fitting of the analytically calculated results to the EM force determined with a 3D transient analysis
Table 1. Current ratios calculated to determine an impulse on the projectile of $200 \mathrm{Ns}$ for the theoretically best geometry and the corresponding maximum total EM forces on the rails

\begin{tabular}{|c|c|c|c|c|c|c|c|}
\hline IR $(\mathrm{kA})$ & 300 & 350 & 400 & 450 & 500 & 550 & 600 \\
\hline IA $(\mathrm{kA})$ & 1518 & 1243 & 1030 & 857 & 713 & 589 & 480 \\
\hline $\mathrm{F}(\mathrm{MN} / \mathrm{m})$ & 11,9 & 9,2 & 7,5 & 6,3 & 5,5 & 4,9 & 4,5 \\
\hline
\end{tabular}

geometry and currents (Fig. 1). The results of the transient analysis are first in good agreement with the results calculated for $1 \mathrm{kHz}$, then decrease to converge with the results for $10 \mathrm{~Hz}$. The fitted curve calculated with the values of the inductances linearly decreasing from the values calculated for $1 \mathrm{kHz}$ at $0.3 \mathrm{~ms}$ to the values for $10 \mathrm{~Hz}$ at $2.0 \mathrm{~ms}$, shows a good overall agreement. This method is used to calculate the EM forces for the different geometries.

The EM forces on the rails and on the projectile are increasing with decreasing distance between the rails $a$ and height $h$. The force on the projectile is decreasing faster for increasing a and $h$ then the force on the rails. The best ratio of the EM force on the projectile and the EM forces on the rails is found at $\mathrm{a}=2 \mathrm{~mm}$ and $\mathrm{h}=2 \mathrm{~mm}$. The optimal width $b$ is not so easy to find. The maximal EM force on the projectile for $\mathrm{a}=2 \mathrm{~mm}$ and $\mathrm{h}=2 \mathrm{~mm}$ is found at $8 \mathrm{~mm}$ for all current ratios. The maximum of the EM force on the rails depends on the current ratio. Another point of interest is the EM forces on the inner rails. If $b$ is chosen too small, we will need a high current in the inner rails to avoid EM forces on the inner rails that point inwards. We have chosen $b=8 \mathrm{~mm}$ to optimize the EM force on the projectile.

To obtain a muzzle velocity of $1 \mathrm{~km} / \mathrm{s}$ for a projectile of $200 \mathrm{~g}$ or a muzzle velocity of $2 \mathrm{~km} / \mathrm{s}$ for a projectile of $100 \mathrm{~g}$, the impulse on the projectile must be 200 Ns. Therefore the current ratios needed to obtain this impulse for the best theoretical geometry were determined. The inner current was varied between 300 and $600 \mathrm{kA}$ and the corresponding outer current was calculated (Table 1). The EM forces on the rails decrease with an increasing current in the inner rails. We choose the current ratio with the lowest inner current wherefore the EM force on the rails is smaller than $8 \mathrm{MN} / \mathrm{m}$. But for the current ratio $400 \mathrm{kA} / 1030 \mathrm{kA}$, the EM force on the inner rails points inwards. Therefore the current ratio $450 \mathrm{kA} / 857 \mathrm{kA}$ is chosen as solution.

The obtained solution for an impulse of 200 Ns is a theoretical solution based upon the EM forces on the rails and on the projectile. Other criteria have to be considered for the final construction.

\section{References}

(1) J. Gallant and P. Lehmann : "Experiments with Brush Projectile in a Parallel Augmented Railgun," IEEE Trans. Magn., Vol.41, No.1, pp.188-193 (2005) 


\title{
Preliminary Design of an Augmented Railgun Influence of the Dimensions of the Outer Rails on the Forces Acting on the Projectile and the Rails
}

\author{
Mieke Coffo* Non-member \\ Johan Gallant* Non-member
}

\begin{abstract}
For the preliminary design of an augmented railgun, the electromagnetic repulsive forces on the rails and the self and mutual inductance gradients were determined by simulation. This design is meant for the realization of an augmented railgun at the French-German Research Institute in Saint-Louis, France. The simulated railgun has a $25 \mathrm{~mm} \times 25 \mathrm{~mm}$ square calibre and both the inner and outer rails have a rectangular cross-section. In our study the geometry of the inner rails is fixed while the dimensions of the outer rails were altered. A 2D transient analysis for the determination of the magnetic forces on the rails was carried out with the finite element method program ANSYS. The EM force on the projectile is analytically calculated with the force-equation based on values of the inductance gradients determined with 3D AC-analyses. The influence of the ratio between the currents in the inner and outer rails on the electromagnetic forces has also been investigated. We have shown that the EM force acting on the projectile increases when the height of the outer rails and the distance between the inner and outer rails decrease. However this also leads to higher repulsive forces between the rails. For the theoretically best geometry, based on the electromagnetic forces, a 3D transient analysis was carried out. The electromagnetic force determined directly with the 3D transient analysis is then compared with the one obtained with the analytical method. A good agreement was found.
\end{abstract}

Keywords : rail launchers, electromagnetic forces, ANSYS

\section{Introduction}

Compared with conventional guns, electromagnetic guns have a high muzzle velocity. Another advantage is the decrease in vulnerability due to the absence of powder. Throughout the years many different types of EM guns and energy storage have been developed. An overview can be found in Ref. (1) and (2).

Railguns are electromagnetic launch systems which have the potential to accelerate projectiles to velocities higher than $2 \mathrm{~km} / \mathrm{s}$. The acceleration of the projectile is the result of the interaction of the current through the brush armature with the magnetic field induced by the current in the rails. For a conventional railgun, raising the current is the only way to increase the electromagnetic force on the projectile. The current density however is limited: the heating of the sliding contacts between the rails and the brush armatures due to the Joule-effect and to the friction can cause the melting of these contacts. Current transition results in an increase of the armature resistance and the deterioration of the rails ${ }^{(3)}$.

One way to increase the acceleration without raising the current through the projectile is by adding an extra pair of rails in order to establish an additional magnetic field. The electromagnetic force on the projectile for an augmented railgun is described by the force-equation:

$$
\mathrm{F}_{\mathrm{EM}}=1 / 2 \mathrm{~L}_{\mathrm{R}} \mathrm{I}_{\mathrm{R}}{ }^{2}+\mathrm{M}^{\prime} \mathrm{I}_{\mathrm{R}} \mathrm{I}_{\mathrm{A}}
$$

The first term represents the magnetic field induced by the current in the inner rails and is proportional to the self inductance gradient $L_{R}{ }_{R}$. The second term describes the influence of an

\footnotetext{
* Department of Weapon Systems and Ballistics, Royal Military Academy
}

Av de la Renaissance, 1000 Brussels, Belgium additional magnetic field and is proportional to the mutual inductance gradient $M^{\prime}$. $I_{R}$ and $I_{A}$ are respectively the currents in the inner and outer rail.

The current in the outer rail, and thus the magnetic field, is limited by the electromagnetic forces on the rails. In this paper we investigate the influence of the dimensions of the outer rail on the electromagnetic forces on the projectile and on the rails for an

b
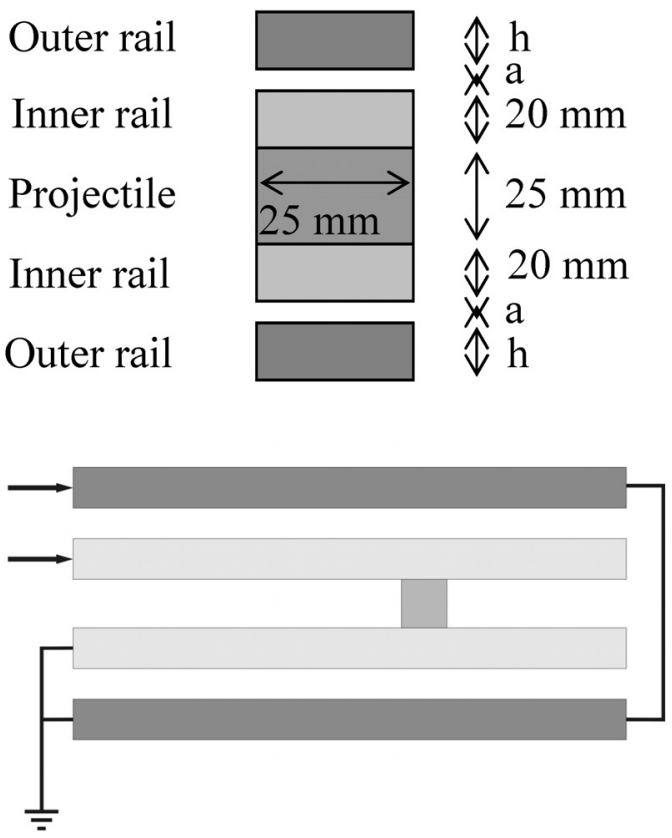

Fig. 1. Front and lateral view of an augmented railgun 
augmented railgun. A similar preliminary study is described in Ref. (4).

The objectives of this preliminary study are to design an augmented rail gun capable of accelerating projectiles with a mass of 100 to $200 \mathrm{~g}$ to a velocity of 1 to $2 \mathrm{~km} / \mathrm{s}$, with the condition that the electromagnetic forces on the rails must be limited to $8 \mathrm{MN} / \mathrm{m}$.

\section{Simulations}

The finite element code program ANSYS was used for the simulation of the magnetic fields. Three different material types are simulated. The air is simulated as a material with relative magnetic permeability of 1 . The rails have an electrical resistivity of $2 \mathrm{e}-8 \Omega . \mathrm{m}$ and a relative magnetic permeability of 1 . The projectile has an electrical resistivity of $2.6667 \mathrm{e}-8 \Omega$.m and again a relative magnetic permeability of 1 .

2.1 Currents For the simulations three current ratios are used. The amplitudes for the inner rails are chosen. The currents in the outer rails are determined in order to have the same impulse on the projectile for each current ratio. The calculations were made so that a muzzle velocity of $2 \mathrm{~km} / \mathrm{s}$ is reached for a projectile with a mass of $200 \mathrm{~g}$. For dc-currents in the inner rail with amplitudes of $400 \mathrm{kA}, 500 \mathrm{kA}$ and $600 \mathrm{kA}$ the corresponding amplitudes for the outer rails, with $L_{R}^{\prime}=0.4 \mu \mathrm{H} / \mathrm{m}$ and $\mathrm{M}^{\prime}=0.2 \mu \mathrm{H} / \mathrm{m}$, are respectively $1267 \mathrm{kA}, 833 \mathrm{kA}$ and $511 \mathrm{kA}$.

The simulated railgun is a parallel augmented railgun. The inner and outer rails have a separate Pulse Forming Network. The currents for the transient analysis are a LabView simulation of these Pulse Forming Networks. Each PFN consists of five capacitor banks. A description of these capacitor banks can be found in Ref. (5). The results are represented in Fig. 2. These currents are multiplied with a factor to correspond with the different current ratios.

2.2 Electromagnetic Forces on the Rails The forces acting on the rails are determined with a $2 \mathrm{D}$ transient analysis. In a 2D analysis only the rails are simulated. The dimensions of the inner rail are fixed at $25 \mathrm{~mm} \times 20 \mathrm{~mm}$. The width of the outer rails is altered from 2 to $40 \mathrm{~mm}$ and the height from 2 to $30 \mathrm{~mm}$ with steps of $2 \mathrm{~mm}$. The distance between the rails is varied between 1 $\mathrm{mm}$ to $15 \mathrm{~mm}$ in steps of $1 \mathrm{~mm}$. The rails are surrounded by a cylinder of air. Only a quarter of the total geometry is simulated. Since the electromagnetic force on the elements is a direct outcome from the simulations with the finite element code ANSYS, no further calculations have to be made.

\subsection{Electromagnetic Force on the Projectile: $L_{R}{ }_{R}, M$ '}

It is possible to determine the force on the projectile directly with a $3 \mathrm{D}$-simulation of the rails and the projectile in the same way as the forces on the rails in a $2 \mathrm{D}$-simulation. But a $3 \mathrm{D}$ transient analysis for all geometries is time-consuming and is only carried out for the most promising geometry. Instead the electromagnetic force on the projectile is analytically calculated with the force-equation. Therefore we need to determine the inductance gradients $L_{R}$ and $M$ '.

The values of $\mathrm{L}_{\mathrm{R}}$ and $\mathrm{M}$ ' are determined with a $3 \mathrm{D}$ AC-analysis at frequencies of $10 \mathrm{~Hz}$ and $1 \mathrm{kHz}$. The geometry of the inner rails was fixed at $25 \mathrm{~mm} \times 20 \mathrm{~mm} \times 139 \mathrm{~mm}$. The length of the outer rail was $140 \mathrm{~mm}$. The width $\mathrm{b}$ was altered from 2 to $30 \mathrm{~mm}$ and the height $\mathrm{h}$ from 2 to $20 \mathrm{~mm}$ in steps of $2 \mathrm{~mm}$. The distance between the rails a was altered from 2 to $6 \mathrm{~mm}$ in steps of $1 \mathrm{~mm}$. Again only a quarter of the geometry is simulated. The currents are placed on the rails in the same way as in the $2 \mathrm{D}$ transient

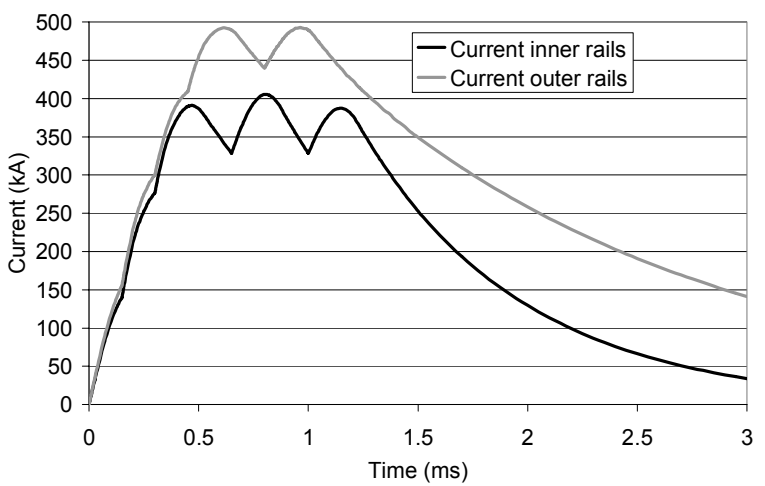

Fig. 2. Current profiles for the currents in the inner and outer rails simulated with LabView

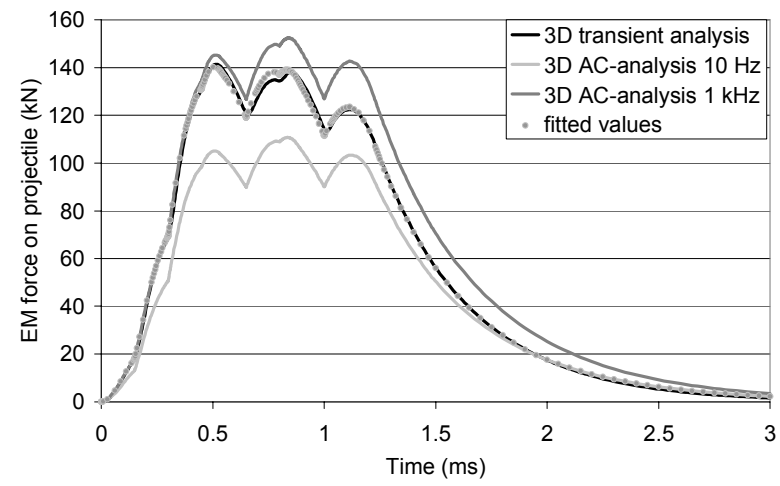

Fig. 3. Electromagnetic force on the projectile: Fitting of the analytically calculated results to the electromagnetic force determined with a $3 \mathrm{D}$ transient analysis

analysis.

For each geometry and frequency we have determined the electromagnetic force for the three current ratios with ANSYS. The force on the projectile is defined by Eq. (1). This allows us to determine $L_{R}$ and $M$ ' for each geometry at both frequencies by fitting $^{(6)}$.

A 3D transient analysis was then carried out for an outer rail with dimensions $20 \mathrm{~mm} \times 20 \mathrm{~mm} \times 140 \mathrm{~mm}$ and a distance of 5 $\mathrm{mm}$ between the inner and outer rail. The values for $\mathrm{L}_{\mathrm{R}}$ and $\mathrm{M}$ ' for this geometry and the currents for the transient analysis are used to calculate the electromagnetic force on the projectile at each step for the current ratio $400 \mathrm{kA} / 1267 \mathrm{kA}$ and for both frequencies. The results are represented in Fig. 3. The results of the transient analysis are in good agreement with the results calculated for $1 \mathrm{kHz}$ until $0.3 \mathrm{~ms}$, then decrease to converge with the results for $10 \mathrm{~Hz}$ at $2.0 \mathrm{~ms}$.

The fourth curve represents the results calculated with the values of the inductances linearly decreasing from the values calculated for $1 \mathrm{kHz}$ at $0.3 \mathrm{~ms}$ to the values for $10 \mathrm{~Hz}$ at $2.0 \mathrm{~ms}$ and shows a good agreement. This method is used to calculate the electromagnetic forces for the different geometries and allows us to make an estimation of the maximal force and the impulse on the projectile.

\section{Results}

3.1 Electromagnetic Forces on the Rails The EM forces on the inner and outer rails calculated with ANSYS refer to the force on one inner or outer rail. The inner and outer rail at one 


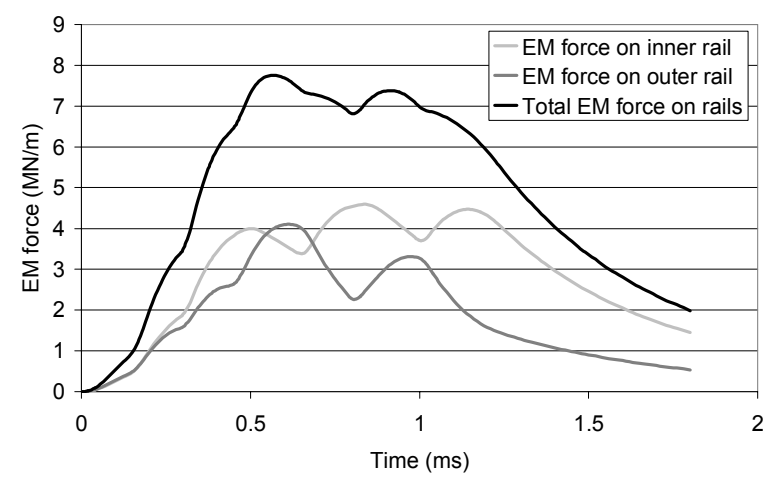

Fig. 4. Electromagnetic forces on the rails for a large outer rail $(24 \mathrm{~mm} \times 20 \mathrm{~mm})$ and $\mathrm{I}_{\mathrm{R}}=400 \mathrm{kA}$ and $\mathrm{I}_{\mathrm{A}}=1267 \mathrm{kA}$ determined with a $2 \mathrm{D}$ transient analysis

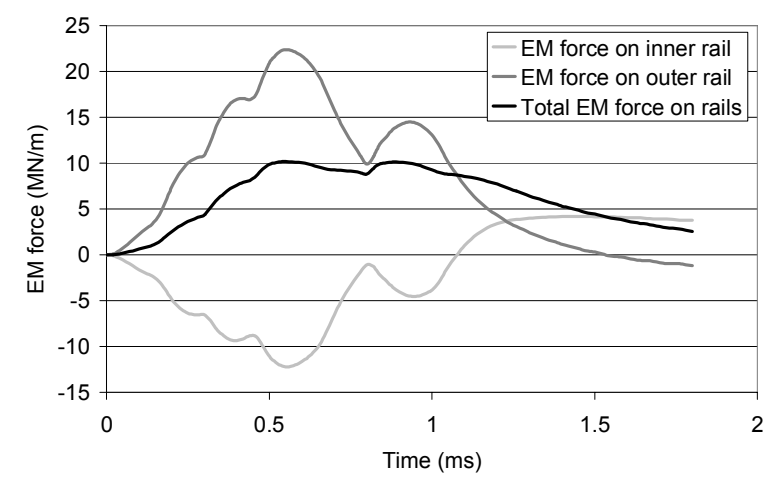

Fig. 5. Electromagnetic forces on the rails for a small outer rail $(2 \mathrm{~mm} \times 2 \mathrm{~mm})$ and $\mathrm{I}_{\mathrm{R}}=400 \mathrm{kA}$ and $\mathrm{I}_{\mathrm{A}}=1267 \mathrm{kA}$ determined with a $2 \mathrm{D}$ transient analysis

side of the projectile are imbedded in a housing.

The results of our calculations with ANSYS point out that the total electromagnetic force on the rails is decreasing with increasing current ratio. When we take a look at the results for a large outer rail for the different current ratios, we see that the difference in the total electromagnetic force is mainly due to the difference in the electro-magnetic force on the outer rails. Fig. 4 represents the results for an outer rail of $24 \mathrm{~mm} \times 20 \mathrm{~mm}$ and a distance between the rails of $\mathrm{a}=5 \mathrm{~mm}$ for $\mathrm{I}_{\mathrm{R}}=400 \mathrm{kA}$ and $\mathrm{I}_{\mathrm{A}}=$ $1267 \mathrm{kA}$. The shapes of the force curves for the inner and outer rail are similar to the current profiles for the inner and outer rail. For this current ratio and for $I_{R}=500 \mathrm{kA}$ and $\mathrm{I}_{\mathrm{A}}=833 \mathrm{kA}$ the electromagnetic force on the outer rails has a positive sign (outwards). For $\mathrm{I}_{\mathrm{R}}=600 \mathrm{kA}$ and $\mathrm{I}_{\mathrm{A}}=511 \mathrm{kA}$ the electromagnetic force on the outer rail has a negative sign and the shape is similar to the shape of the current profile of $I_{R}$. The electromagnetic force on the inner rail has always a positive sign.

The force curves for a small outer rail $(2 \mathrm{~mm} \times 2 \mathrm{~mm})$ and a distance $\mathrm{a}=1 \mathrm{~mm}$ tell another story. For the current ratios 400 kA/1267 kA (Fig. 5) and $500 \mathrm{kA} / 833 \mathrm{kA}$ the EM force on the inner rail becomes negative and the shape is similar to the shape of the electromagnetic force on the outer rails but have an opposite sign. The current densities in the rails for these geometries with current ratio $400 \mathrm{kA} / 1267 \mathrm{kA}$ show that the negative currents induced in the inner rail by the outer rail current are well spread at the upper surface of the rail. For a small outer rail the induced current is concentrated at the middle of the upper surface of the rail close to the outer rail with current densities higher then those
Table 1. Values and positions of the overall maxima for the total electromagnetic force on the rails

\begin{tabular}{|c|c|c|c|c|}
\hline $\begin{array}{c}\text { Total EM Force } \\
\text { on rails }\end{array}$ & Maximum & $\mathrm{b}$ & $\mathrm{h}$ & $\mathrm{a}$ \\
\hline $\begin{array}{l}\mathrm{I}_{\mathrm{R}}=400 \mathrm{kA} \\
\mathrm{I}_{\mathrm{A}}=1267 \mathrm{kA}\end{array}$ & $10,4 \mathrm{MN} / \mathrm{m}$ & $14 \mathrm{~mm}$ & $2 \mathrm{~mm}$ & $1 \mathrm{~mm}$ \\
\hline $\begin{array}{l}\mathrm{I}_{\mathrm{R}}=500 \mathrm{kA} \\
\mathrm{I}_{\mathrm{A}}=833 \mathrm{kA}\end{array}$ & $6,76 \mathrm{MN} / \mathrm{m}$ & $12 \mathrm{~mm}$ & $2 \mathrm{~mm}$ & $1 \mathrm{~mm}$ \\
\hline $\mathrm{I}_{\mathrm{R}}=600 \mathrm{kA}$ & $4,85 \mathrm{MN} / \mathrm{m}$ & $2 \mathrm{~mm}$ & $2 \mathrm{~mm}$ & $1 \mathrm{~mm}$ \\
$\mathrm{I}_{\mathrm{A}}=511 \mathrm{kA}$ & & & & \\
\hline
\end{tabular}

of the injected current concentrated in the corners at the side of the projectile. Since the magnetic field is inversely proportional to the square of the distance, this explains why the magnetic force on the inner rails is negative (inwards). For construction reasons, negative forces on the inner rails have to be avoided.

To compare the forces on the rails we determined the maximum total force for each geometry and current ratio. The total electromagnetic force on the rails is decreasing with increasing height $\mathrm{h}$ and distance between the rails a. For the current ratio 600 $\mathrm{kA} / 511 \mathrm{kA}$ the maximal total force in function of the width is found at $b=2 \mathrm{~mm}$. For the two other current ratios the force curve in function of the width goes through a maximum. This is a result of the negative electromagnetic forces on the inner rail. The overall maxima of the total magnetic force are listed in Table 1. The lowest maximum $4.85 \mathrm{MN} / \mathrm{m}$ is found for the highest current ratio $600 \mathrm{kA} / 511 \mathrm{kA}$. The maximum $6.76 \mathrm{MN} / \mathrm{m}$ found for 500 $\mathrm{kA} / 833 \mathrm{kA}$ is about $40 \%$ higher and the maximum $10.4 \mathrm{MN} / \mathrm{m}$ for $400 \mathrm{kA} / 1267 \mathrm{kA}$ is more then two times higher then the one found for the highest current ratio.

3.2 $L_{\mathbf{R}}^{\prime}$ and $M$ ' First we discuss the values of the inductance gradients found with the AC-analyses at $10 \mathrm{~Hz}$ and 1 $\mathrm{kHz}$. The inductance gradients $\mathrm{L}_{\mathrm{R}}$ found for $10 \mathrm{~Hz}$ fluctuate around $0.43 \mu \mathrm{H} / \mathrm{m}$ and do not show much variation in function of the width $b$, the height $h$ and the distance a. The values for $L_{R}$ at 1 $\mathrm{kHz}$ decrease slightly with increasing width $\mathrm{b}$ and height $\mathrm{h}$ and decreasing distance a and vary between $0.40-0.44 \mu \mathrm{H} / \mathrm{m}$.

The mutual inductance gradient $\mathrm{M}^{\prime}$ decreases with increasing height $h$ and distance a for both frequencies. At $10 \mathrm{~Hz} \mathrm{M}^{\prime}$ is slightly decreasing with increasing width $\mathrm{b}$. At $1 \mathrm{kHz}$ the values for $\mathrm{M}^{\prime}$ go through a maximum in function of the width $\mathrm{b}$. The mutual inductances vary between $0.16-0.26 \mu \mathrm{H} / \mathrm{m}$ at $10 \mathrm{~Hz}$ and between $0.25-0.38 \mu \mathrm{H} / \mathrm{m}$ at $1 \mathrm{kHz}$.

3.3 Electromagnetic Force on the Projectile Once the inductance gradients are determined we can calculate analytically the electromagnetic force on the projectile. The fitted values for $\mathrm{M}^{\prime}$ and $\mathrm{L}_{\mathrm{R}}$ and the currents for the transient analyses are used. To compare the results we determine the maximum electromagnetic force on the projectile for each geometry and at each current ratio. Notice that we can calculate the electromagnetic force on the projectile for any current ratio we want.

The maximum electromagnetic force on the projectile is decreasing with increasing height $\mathrm{h}$ and distance a for all current ratios. The values in function of the width $b$ go through $a$ maximum and show a dip at $b=14 \mathrm{~mm}$ like the values for $\mathrm{M}^{\prime}$ at 1 $\mathrm{kHz}$.

The overall maxima are presented in Table 2. The lowest maximum is found for $600 \mathrm{kA} / 511 \mathrm{kA}$. The maxima found for 400 $\mathrm{kA} / 1267 \mathrm{kA}$ and $500 \mathrm{kA} / 833 \mathrm{kA}$ are respectively $13 \%$ and $6 \%$ higher. 
Table 2. Values and positions of the overall maxima for the electromagnetic force on the projectile

\begin{tabular}{|c|c|c|c|c|}
\hline $\begin{array}{c}\text { EM force on } \\
\text { projectile }\end{array}$ & Maximum & $\mathrm{b}$ & $\mathrm{h}$ & $\mathrm{a}$ \\
\hline $\begin{array}{l}\mathrm{I}_{\mathrm{R}}=400 \mathrm{kA} \\
\mathrm{I}_{\mathrm{A}}=1267 \mathrm{kA}\end{array}$ & $195 \mathrm{kN}$ & $8 \mathrm{~mm}$ & $2 \mathrm{~mm}$ & $2 \mathrm{~mm}$ \\
\hline $\begin{array}{l}\mathrm{I}_{\mathrm{R}}=500 \mathrm{kA} \\
\mathrm{I}_{\mathrm{A}}=833 \mathrm{kA}\end{array}$ & $184 \mathrm{kN}$ & $8 \mathrm{~mm}$ & $2 \mathrm{~mm}$ & $2 \mathrm{~mm}$ \\
\hline $\mathrm{I}_{\mathrm{R}}=600 \mathrm{kA}$ & $173 \mathrm{kN}$ & $8 \mathrm{~mm}$ & $2 \mathrm{~mm}$ & $2 \mathrm{~mm}$ \\
$\mathrm{I}_{\mathrm{A}}=511 \mathrm{kA}$ & & & & \\
\hline
\end{tabular}

\subsection{Impulse The impulse can be calculated by} integration of the analytically determined force curve. To obtain a muzzle velocity of $1 \mathrm{~km} / \mathrm{s}$ for a projectile with a mass of $200 \mathrm{~g}$ or a muzzle velocity of $2 \mathrm{~km} / \mathrm{s}$ for a projectile of $100 \mathrm{~g}$ the impulse on the projectile must be 200 Ns. A muzzle velocity of $2 \mathrm{~km} / \mathrm{s}$ for a projectile with a mass of $200 \mathrm{~g}$ requires an impulse of $400 \mathrm{Ns}$.

For a chosen impulse, the outer rail current can be calculated if the inner rail current is fixed.

\section{Determination of the Theoretically Best Geometry}

With the theoretically best geometry we mean the best geometry found based upon the electromagnetic forces on the rails and on the projectile. To obtain the impulses mentioned above we have to maximize the force on the projectile. But high electromagnetic forces on the projectile mean also high electromagnetic forces on the rails. We fix the limit for the electromagnetic force on the rails at $8 \mathrm{MN} / \mathrm{m}$ for construction reasons. Therefore we have to find a balance between the electromagnetic forces on the rails and the electromagnetic force on the projectile.

The electromagnetic forces on the rails just as the electromagnetic force on the projectile are increasing with decreasing distance between the rails a and height $h$. The force on the projectile is decreasing faster for $\mathrm{a}$ and $\mathrm{h}$ than the force on the rails. The best ratio of the force on the projectile and the forces on the rails is found at a distance between the rails of $\mathrm{a}=2 \mathrm{~mm}$ and and a height of $\mathrm{h}=2 \mathrm{~mm}$.

The optimal width $b$ is not so easy to find. The maximal electromagnetic forces on the projectile for $\mathrm{a}=2 \mathrm{~mm}$ and $\mathrm{h}=2$ $\mathrm{mm}$ is found at $8 \mathrm{~mm}$ for all three current ratios. The maximum of the electromagnetic force on the rails depends on the current ratio. The best ratio of the force on the projectile and the forces on the rails is found at $\mathrm{b}=8 \mathrm{~mm}$ for the current ratios $600 \mathrm{kA} / 511 \mathrm{kA}$ and $500 \mathrm{kA} / 833 \mathrm{kA}$ and at $\mathrm{b}=2 \mathrm{~mm}$ for $400 \mathrm{kA} / 1267 \mathrm{kA}$. Another point of interest are the electromagnetic forces on the inner rail. If the width $b$ is chosen too small, we will need a high current in the inner rail to avoid negative electromagnetic forces in the inner rails. We have chosen $\mathrm{b}=8 \mathrm{~mm}$ to optimize the electromagnetic force on the projectile.

\section{3D transient Analysis of the Theoretical Solution}

5.1 Determination of the Current Ratios We first have to optimize the current ratios needed to obtain the desired impulses for the best theoretical geometry. For an impulse of 200 Ns we vary the inner current between 300 and $600 \mathrm{kA}$ and calculated the corresponding outer current. For these current ratios a 2D transient analysis was carried out to determine the corresponding electromagnetic forces on the rails. The results of this calculations are listed in Table 3.

The electromagnetic forces on the rails decrease with an
Table 3. Current ratios calculated to determine an impulse on the projectile of $200 \mathrm{Ns}$ for the theoretically best geometry and the corresponding maximum total electromagnetic forces on the rails

\begin{tabular}{|c|c|c|c|c|c|c|c|}
\hline$I_{R}(k A)$ & 300 & 350 & 400 & 450 & 500 & 550 & 600 \\
\hline$I_{A}(k A)$ & 1518 & 1243 & 1030 & 857 & 713 & 589 & 480 \\
\hline$F(M N / m)$ & 11,9 & 9,2 & 7,5 & 6,3 & 5,5 & 4,9 & 4,5 \\
\hline
\end{tabular}

Table 4. Current ratios calculated to determine an impulse on the projectile of $400 \mathrm{Ns}$ for the theoretically best geometry and the corresponding maximum total electromagnetic forces on the rails

\begin{tabular}{|c|c|c|c|c|c|c|c|}
\hline $\mathrm{I}_{\mathrm{R}}(\mathrm{kA})$ & 550 & 600 & 650 & 700 & 750 & 800 & 850 \\
\hline $\mathrm{I}_{\mathrm{A}}(\mathrm{kA})$ & 1518 & 1332 & 1170 & 1027 & 898 & 782 & 676 \\
\hline $\mathrm{F}(\mathrm{MN} / \mathrm{m})$ & 15,6 & 13,7 & 12,3 & 11,2 & 10,2 & 9,6 & 9,0 \\
\hline
\end{tabular}

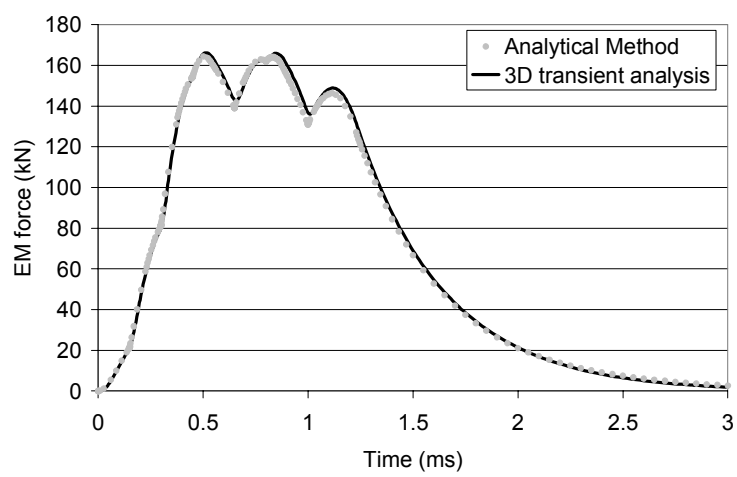

Fig. 6. Comparison of the electromagnetic force on the projectile calculated analytically with the force-equation and determined directly with a $3 \mathrm{D}$ transient analysis

increasing current in the inner rails. Since limiting the current in the inner rails is the main reason why we want to design an augmented railgun, we choose the current ratio with the lowest inner current wherefore the electromagnetic force on the rails is smaller than $8 \mathrm{MN} / \mathrm{m}$. But for the current ratio $400 \mathrm{kA} / 1030 \mathrm{kA}$ there is a significant negative force on the inner rails. The results for $450 \mathrm{kA} / 857 \mathrm{kA}$ show only a low negative electromagnetic force on the inner rail at the very beginning of the analysis and this current ratio is chosen as solution.

For an impulse of 400 Ns the inner current is varied between $550 \mathrm{kA}$ and $850 \mathrm{kA}$ and the corresponding outer currents are calculated. The electromagnetic forces on the rails are again simulated with a 2D transient analysis (Table 4). The limit of $8 \mathrm{MN} / \mathrm{m}$ is not achieved for a reasonable inner current.

5.2 Electromagnetic Force and Impulse on the Projectile

A 3D transient analysis was carried out for the best theoretical geometry for the current ratio $450 \mathrm{kA} / 857 \mathrm{kA}$. The electromagnetic force on the projectile obtained with this analysis is compared with the results of the analytical method (Fig. 6) and a good agreement is found. The difference between the electromagnetic forces on the projectile calculated with both methods is within $2 \%$. The current ratio $450 \mathrm{kA} / 857 \mathrm{kA}$ was optimized to obtain an impulse of 200 Ns. The impulse based on the results of the 3D transient analysis, calculated as control, is 202 . 


\section{Discussions}

For the construction of an augmented railgun the influence of the geometry of the outer rail on the magnetic forces on the projectile was studied. The objective is a muzzle velocity of 1-2 $\mathrm{km} / \mathrm{s}$ for a projectile with a mass of $100-200 \mathrm{~g}$ and electromagnetic forces on the rails lower than $8 \mathrm{MN} / \mathrm{m}$.

A 2D transient analysis was carried out for the determination of the electromagnetic force on the rails. The total electromagnetic force on the rails decreases with increasing height $\mathrm{h}$ and distance $\mathrm{a}$. The lowest overall maximum is found for the current ratio with the highest inner rail current. The width $b$ where the overall maxima are found is depending on the current ratio.

The electromagnetic force on the projectile was analytically calculated with the force-equation. The coefficients of this force-equation $\mathrm{L}_{\mathrm{R}}$ and $\mathrm{M}$ ' were determined with $3 \mathrm{D} \mathrm{AC}$ analyses at $10 \mathrm{~Hz}$ and $1 \mathrm{kHz}$. The force on the projectile decreases with increasing height $\mathrm{h}$ and distance $\mathrm{a}$. The overall maxima were found at $\mathrm{b}=8 \mathrm{~mm}$. The electromagnetic force on the projectile is increasing with decreasing current ratio.

To determine the theoretically best geometry a balance between the electromagnetic forces on the rails and on the projectile has to been found. The electromagnetic force on the projectile is faster decreasing with the distance $a$ and the height $h$ than the electromagnetic force on the rails. The width $b$ was optimized to obtain a maximum force on the projectile. The theoretically best geometry is then $\mathrm{a}=2 \mathrm{~mm}, \mathrm{~h}=2 \mathrm{~mm}$ and $\mathrm{b}=8 \mathrm{~mm}$.

Then we determined the best current ratio for this geometry to obtain an impulse of 200Ns. A 3D transient analysis was carried out for the theoretically best geometry. The difference between the directly determined and the analytically calculated force on the projectile is within $2 \%$ and the determined impulse is $202 \mathrm{Ns}$. The maximum total electromagnetic force on the rails is $6.3 \mathrm{MN} / \mathrm{m}$ for this configuration.

For an impulse of $400 \mathrm{Ns}$ the limit of $8 \mathrm{MN} / \mathrm{m}$ for the electromagnetic force on the rails was not achieved for an acceptable inner current.

The obtained solution for an impulse of $200 \mathrm{Ns}$ is a theoretical solution based upon the electromagnetic forces on the rails and on the projectile. Other criteria have to be considered for the final construction, like the mechanical feasibility and the maximal current density.

(Manuscript received March 6, 2007, revised June 26, 2007)

\section{References}

(1) I. R. McNab : "Pulsed Power for Electric Guns", IEEE Trans. Magn., Vol.33, No.1, pp.453-460 (1997-1)

(2) I. R. McNab : "Early Electric Gun Research", IEEE Trans. Magn., Vol.35, No.1, pp.250-261 (1999-1)

(3) J. P. Barber and I. R. McNab : "Magnetic Blow-Off in Armature Transition", IEEE Trans. Magn., Vol.39, No.1, pp.42-46 (2003-1)

(4) J. Gallant : "Parametric Study of an Augmented Railgun", IEEE Trans. Magn., Vol.39, No.1, pp.451-455 (2003-1)

(5) J. Gallant : 'Le lanceur électromagnétique à rails augmenté : modélisation et validation expérimentale', $\mathrm{PhD}$ Thesis, Université de Franche-Comté, pp.87-89 (2004)

(6) J. Gallant and P. Lehmann : "Experiments with Brush Projectiles in a Parallel Augmented Railgun", IEEE Trans. Magn., Vol.41, No.1, pp.188-193 (2005-1)

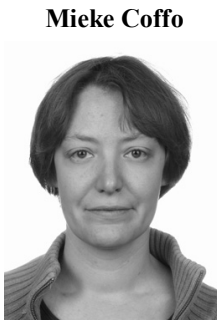

(Non-member) was born in Aalst, Belgium, on August 16, 1977. She received her Master of Engineering Physics from Ghent University, Ghent, Belgium in 2002 and her Master of Biomedical and Clinical Engineering from Ghent University, Ghent, Belgium in 2004. Since 2005 , she is a researcher at the department of Weapon Systems and Ballistics of the Royal Military Academy, Brussels, Belgium and engaged in the research on electromagnetic railguns.

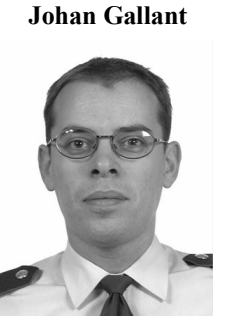

(Non-member) was born in Ghent, Belgium, on June 22, 1970. He received his M.Sc. in ballistics from the Royal Military Academy, Brussels, Belgium in 1994 and obtained his $\mathrm{PhD}$ in Electrotechnical Engineering from the University of Besançon, France in 2004. Since 1997, he is assistant in the department of Weapon Systems and Ballistics of the Royal Military Academy and engaged in the research on electromagnetic railguns. 